\title{
TEMPO NÃO É EVIDÊNCIA: UMA ANÁLISE ACERCA DO TEMPO PROCESSUAL COMO FUNDAMENTO DA TUTELA PROVISÓRIA BASEADA EM EVIDÊNCIA DO ARTIGO 311 DO CPC ${ }^{1}$
}

\author{
TIME IS NOT EVIDENCE: A ANALYSIS ABOUT THE PROCESS TIME AS \\ GROUND OF THE PROVISIONAL INJUCTION BASED IN EVIDENCE, \\ PROVIDED FOR ARTICLE 311 OF BRAZILIAN CIVIL PROCEDURE CODE
}

Volnei Rosalen

Mestre em Direito Político e Econômico (Mackenzie/SP), Doutorando em Direito (Ufsc), professor universitário, membro do Grupo de Pesquisa em Constitucionalismo Político (Ufsc). Universidade Federal de Santa Catarina - UFSC. Florianópolis/SC. E-mail: volneirosalen77@gmail.com.

RESUMO: A tutela da evidência, incorporada de forma explícita ao quadro das técnicas de tutela provisória no CPC de 2015, toma como pressuposto a ideia de existência de um direito evidente do autor da ação, que justifica maior efetividade da prestação jurisdicional nos casos previstos na lei processual. "Direito líquido e certo" e "direito evidente" devem estar associados às "evidências" que os suportam, ou seja, às provas. A fundamentação da tutela da evidência em uma eventual melhora do tempo do processo, embora política, econômica e sociologicamente defensáveis, não constituem elemento processual chave para a decisão da concessão da tutela. $\mathrm{O}$ artigo aborda esta questão, dialogando com visões doutrinárias a respeito.

PALAVRAS-CHAVE: Tutela da evidência. Direito evidente. Direito líquido e certo. Tempo do processo. Tempo não é evidência.

ABSTRACT: The evidence injuction, embody in explicit form to frame of the provisional measure technique on CPC of the 2015, takes for granted the idea of existence of a obvious

\footnotetext{
${ }^{1}$ Artigo recebido em 27/01/2020 e aprovado em 26/01/2021.
} 
right of the demandant, which justifies greater effectiveness of the adjudication in the cases provided by procedural law. "Clear legal right" and "obvious right" must be connected to "evidences" which sustain it, that is, the evidences. The statement of the evidence injuction in a possible improvement of process time, although politically, economically and sociologically tenable, does not constitute procedural key piece for the decision of the adjudication. The paper adresses this issue, dialoguing with doctrinal view about.

KEYWORDS: Evidence injuction. Evident right. Clear legal right. Process time. Time is not evidence.

\section{INTRODUÇÃO.}

Ao entrar em vigor em 2015, o novo Código de Processo Civil destacou a chamada tutela da evidência em relação à tutela antecipada, distinguindo do tratamento dado pelo Código anterior, e procurando, no plano semântico, introduzir a ideia de um direito que pudesse ser considerado evidente.

No que toca especificamente ao direito considerado evidente em função do abuso de defesa ou manifesto propósito protelatório do réu o que o CPC 2015 fez foi desloca-lo da posição de uma das hipóteses da forma de tutela antecipada do artigo 273, II (CPC/1973), para a posição de uma espécie própria de tutela provisória, a tutela da evidência, figurando como uma espécie de regra base desta.

A ideia de um direito evidente possui uma carga semântica significativamente forte, dado que pressupõe mais do que uma verossimilhança, mas uma altíssima probabilidade de acolhimento do direito no dizer de Eduardo $\mathrm{Lamy}^{2}$, de tal modo que ele possa ser assim considerado como um direito evidente.

Dentre as hipóteses de tutela provisória baseada na evidência, o artigo 311 do CPC enuncia quatro situações legais, inobstante possam outras ser identificadas em localizações diversas daquela lei, como o que ocorre no artigo 700 (relativo à ação monitória). As constantes dos incisos II, III e IV podem ser, para os propósitos do presente artigo, reunidas sob um ponto comum, qual seja, a exigência de que o direito do autor esteja devidamente

\footnotetext{
${ }^{2}$ LAMY, Eduardo. Tutela provisória. São Paulo: Atlas, 2018, p. 13
} 
amparado em prova documental, embora comportem também análises específicas que serão feitas adiante.

A hipótese descrita no inciso I, por sua vez, encarna uma situação aberta, submetida a carga considerável de subjetividade e marcadamente submetida a um fundamento subjacente, na atualidade, a toda a discussão sobre a efetividade da tutela jurisdicional: a efetivação do direito material frente ao tempo de duração do processo.

Naturalmente que o tempo de duração do processo não constitui via única de abordagem sobre a efetivação de alterações no plano do direito material a partir das ferramentas de tutela jurisdicional disponíveis.

Mas, sobretudo a partir da Emenda Constitucional 45/2004, com a inclusão do direito à razoável duração do processo e os meios que garantam a celeridade de sua tramitação no rol dos direitos e garantias fundamentais, como previsto no Art. $5^{\circ}$, LXXVIII da CF, a questão do tempo do processo elevou a pressão para que a tutela jurisdicional, e seus instrumentos e técnicas, bem como a condução do processo pelo juiz, levem em consideração este elemento.

É difícil aferir em que nível a pressão sobre o tempo do processo influencia o comportamento dos juízes, especialmente no plano subjetivo, e sua maneira de conduzir os procedimentos e a tomada de decisões. Mas no plano legislativo é possível encontrar marcas significativas da preocupação como o tempo processual como aspecto relevante à efetividade da tutela dos direitos, como a que aparece nas técnicas de tutela de urgência baseadas no perigo de dano ou risco ao resultado útil do processo, em que o tempo/duração do processo surge como um limitador ou um risco à efetividade da prestação de tutela.

Assim é no caso do inciso do artigo 311, e em especial de sua regra base, no inciso I estabelece sanção às situações hipotéticas de abuso de defesa e de manifesto propósito protelatório da parte faz surgir com clareza a perspectiva de se encurtar o tempo do processo, ou, dito de outra forma, de evitar seu alongamento como uma eventual vantagem à parte.

Mas, em se tratando de direito evidente, (ou de uma tutela provisória baseada em evidência), ou seja, dado que a concessão da tutela provisória baseada em evidência, prevista no artigo 311, e especialmente no inciso I do CPC demanda a comprovação de um direito evidente, é possível situar o tempo do processo, e sua distribuição, como um fundamento (implícito) de tal modalidade de tutela e para sua concessão? 
Este o objeto do presente artigo, utilizando-se como forma de abordagem um diálogo com visões que sustentam a alteração das normas processuais, no plano geral, como assentadas sobre a necessidade de combater a morosidade judicial e que ligam efetividade com tempo processual (especialmente Luiz Fux), e no plano específico da tutela da evidência, como forma de distribuição do ônus do tempo do processo (especialmente Luiz Guilherme Marinoni).

A primeira e a segunda parte do artigo são dedicadas a uma abordagem descritiva do estado da arte da tutela da evidência a partir de autores que tratam do assunto com mais acuidade. E a terceira parte está reservada a uma espécie de polêmica com as ideias de tempo processual como algo decisivo à tutela da evidência.

\section{TUTELA JURISDICIONAL PROVISÓRIA}

De início convém recordar o fato básico de que quando estamos falando de tutela jurisdicional do direito, referimo-nos ao direito como direito positivo, ou seja, como "direito posto pelo poder soberano do Estado, mediante normas geais e abstratas, isto é, como 'lei"', como o descreve Norberto Bobbio. ${ }^{3}$

Assim, como decorrência do direito posto na lei, já se levanta um primeiro modo pelo qual o Estado tutela o direito dos indivíduos, e do qual decorre outros necessários deveres de tutela, como é o caso da tutela jurisdicional. ${ }^{4} \mathrm{E}$ nesta estão contidas as formas tutelares pelas quais o direito se realiza, para além da declaração legislativa ${ }^{5}$.

\footnotetext{
${ }^{3}$ BOBBIO, Norberto. O positivismo jurídico - lições de filosofia do direito. Tradução de Márcio Pugliesi, Edson Bini e Carlos E. Rodrigues. São Paulo: Editora Ícone, 1995.

4 "Como se vê, o Estado tem o dever de tutelar ou proteger os direitos fundamentais através de normas, da atividade administrativa e da jurisdição. Por isso, há tutela normativa, tutela administrativa e tutela jurisdicional dos direitos". (MARINONI, Luiz Guilherme. Tutela de urgência e tutela da evidência - soluções processuais diante do tempo da justiça. São Paulo: Editora Revista dos Tribunais, 2018, p. 25)

5 "Como se vê, a postura dogmática preocupada com as tutelas é atenta para as formas de proteção ou de tutela dos direitos. Ela não está preocupada em saber se os cidadãos têm este ou aquele direito, ou mesmo com a identificação de direitos difusos e coletivos. É que, na perspectiva das "formas de tutela dos direitos", a atribuição de titularidade de um direito fica na dependência de que lhe seja garantida a disponibilidade de uma forma de tutela que seja adequada à necessidade da sua proteção. Ou melhor, o sujeito só é titular de um direito, ou de uma posição jurídica protegida, quando esse direito dispor de uma forma de tutela adequada à necessidade de proteção que esta posição exija". (MARINONI, op. cit., págs. 27/28)
} 
Como decorrência do direito chamado material, previsto na lei como ordenamento positivo, a tutela jurisdicional visa garantir exatamente aquilo que não se pôde obter apenas pela existência da norma legal ${ }^{6}$.

De forma mais completa e abrangente, atendendo a uma perspectiva contemporânea, integrando direito processual e direito constitucional, especialmente no plano dos direitos fundamentais, Eduardo Lamy e Horácio Rodrigues ${ }^{7}$, definem a jurisdição como: "poderdever do estado-juiz de declarar e executar os direitos conforme as pretensões que lhe são formuladas, segundo os valores e princípios fundamentais estabelecidos na Constituição Federal (...)".

De tal maneira que a assim chamada tutela jurisdicional é a forma pela qual o Estado atua tendo como fundamento aplicar o direito e garantir sua eficácia nos conflitos concretos, mediante provocação. ${ }^{8}{ }^{9}$

Na visão contemporânea do processo civil, que considera como finalidade do processo o seu resultado, e mais precisamente um resultado que precisa se realizar no mundo dos fatos, o processo é encarado como um instrumento, figurando os procedimentos e técnicas como meios de atingimento do fim. A tutela jurisdicional do direito material é o fim (ou finalidade) do processo. ${ }^{10}$

\subsection{Tutela definitiva e tutela provisória}

\footnotetext{
6 “O que se busca, portanto, é a tutela, via-atividade jurisdicional do Estado, do que não se pôde obter com o que o ordenamento jurídico, aqui referido sob seu plano material, previa e que poderia ter-se verificado, não fosse um dos fatores indicados pela doutrina para explicar a necessidade do processo e da jurisdição. São necessários 'seja porque (a) aquele que poderia satisfazer a sua pretensão não a satisfaz, seja porque (b) o próprio direito proíbe a satisfação voluntária da pretensão'”. VIGLIAR, José Marcelo Menezes. Tutela Jurisdicional coletiva. São Paulo: Atlas, 2013, p. 24. (A passagem em negrito da citação é atribuída por Vigliar a Cândido Rangel Dinamarco).

${ }^{7}$ LAMY, Eduardo; RODRIGUES, Horácio Wanderlei. Teoria Geral do Processo. 4 ${ }^{\text {a }}$ Edição. São Paulo: Atlas, 2016, p. 169.

${ }^{8}$ Idem, ibidem, p. 170

${ }^{9}$ Cássio Scarpinela Bueno, por sua vez, expõe assim sua visão sobre a tutela jurisdicional: “À luz de tudo quanto escrevi até agora, sublinhando, no particular a idéia de que o processo é mero instrumento do direito material, é o mecanismo pelo qual o direito material controvertido tende a ser realizado e concretizado pela atuação do Estado-juiz, a tutela jurisdicional só pode ser entendida como a realização concreta do direito que foi lesado ou ameaçado". (BUENO, Cássio Scarpinela. Tutela antecipada. 2a . Edição. São Paulo: Saraiva, 2007, p. 23)

${ }^{10}$ LAMY, Eduardo. Considerações sobre a influência dos valores e direitos fundamentais no âmbido da teoria processual. Seqüência (Florianópolis), n. 69, p. 301-326, dez. 2014.
} 
A visão da tutela jurisdicional como fim do processo determinou, na reforma processual aprovada em 2015, uma reconfiguração interna do CPC, cuja estrutura dividiu a tutela jurisdicional em tutela definitiva e tutela provisória.

Tem-se por tutela definitiva aquela efetivada pela execução da decisão jurisdicional final de mérito, como descreve Eduardo Lamy ${ }^{11}$, com o trânsito em julgado da decisão e resolvendo as questões de mérito do processo, conforme elencado no artigo 487 do CPC.

Já a tutela provisória decorre da execução das decisões tomadas em procedimentos de tutela de urgência ou tutela da evidência, de acordo com José Roberto Bedaque. ${ }^{12}$

Enquanto a tutela de urgência implica uma combinação entre plausibilidade do direito e o risco de algum acontecimento que venha a prejudicar ou impedir a efetividade prática da tutela definitiva, a tutela provisória da evidência tem como fundamento na verossimilhança, ou mais precisamente no alto grau de probabilidade do direito material invocado. $^{13}$

Noutro plano, a distinção entre a tutela provisória e a tutela definitiva liga-se à possibilidade de exaurimento ou não da cognição. Ou seja, a tutela definitiva implica a certeza de uma solução definitiva para o conflito de direito material apresentado ao juiz, e, portanto, a chegada a uma sentença de mérito, de modo a haver uma etapa de conhecimento e outra de execução. A tutela provisória, por sua vez, tem como seu fundamento, uma combinação de plausibilidade do direito, ora com o risco de dano ou prejuízo, ora com alto grau de probabilidade do direito invocado, e implica uma combinação de conhecimento e execução em um mesmo processo e sob uma mesma técnica processual.

\subsection{Tutela provisória e técnica processual de cognição sumária}

\footnotetext{
${ }^{11}$ LAMY, Eduardo. Tutela provisória. São Paulo: Atlas, 2018.

12 "Em síntese, essa modalidade de tutela, informada sempre por cognição não exauriente, fundada, portanto, no juízo de verossimilhança, não de certeza, em princípio provisória, destinada a assegurar o resultado útil do processo, comporta duas espécies: as urgentes e as não urgentes. Estas caracterizam-se tão somente pelo grau de evidência do direito afirmado. Possível, então, denominar as tutelas sumárias e provisórias com as seguintes expressões: tutelas de urgência e tutelas da evidência”. (BEDAQUE, José Roberto dos Santos. Tutela provisória: considerações gerais. In: CARMONA, Carlos Alberto et. al. O Novo Código de Processo Civil questões controvertidas. São Paulo: Atlas, 2015. p. 13)

${ }^{13}$ BEDAQUE, op. cit., p. 14.
} 
Como visto, na arquitetura do Código de Processo Civil, a tutela jurisdicional pode ser definitiva ou provisória, sendo que esta última pode se fundamentar na urgência ou na evidência do direito material pleiteado.

Internamente à tutela provisória da urgência é possível reconhecer, como faz Eduardo Lamy o manejo de técnicas processuais diversas para o fim pretendido, com a antecipação de tutela e a técnica antecipatória ${ }^{14}$.

Analisando a questão da relação entre formas de tutela e técnicas processuais, Luiz Guilherme Marinoni apresenta a perspectiva de que deva haver uma relação de adequação entre as tutelas de direitos e as técnicas processuais ${ }^{15}$.

A visão a respeito das técnicas processuais, a despeito das nuances com que é apresentada na doutrina, toma como ponto comum a concepção de instrumentalidade do processo. O processo não é o fim, mas realizado em função de um fim, que é a tutela jurisdicional. Esta, entendida não apenas como a resposta do judiciário, mas a resposta efetiva, que implique uma alteração fática no plano do direito material.

As técnicas processuais, assim, devem ser capazes de prestar as formas de tutela prometidas pelo direito material, conforme afirma Luiz Guilherme Marinoni. ${ }^{16}$

Adotando uma divisão da técnica a partir da cognição, Marinoni classifica a cognição no plano horizontal como plena ou parcial, e no plano vertical, como exauriente, sumária e superficial. ${ }^{17}$

Assim, no plano vertical, sob a técnica da cognição sumária, estariam situados os juízos de probabilidade, dado que o a restrição da cognição não importaria a certeza de uma cognição exauriente e definitiva, mas o alto grau de probabilidade do direito.

Sob a cognição sumária estariam, então, as tutelas de urgência e da evidência. A primeira podendo ser efetivada através das técnicas de tutela antecipada antecedente e tutela

\footnotetext{
${ }^{14} \mathrm{~A}$ técnica cautelar e a técnica antecipatória são as mais importantes e utilizadas técnicas de urgência. (LAMY, 2018, op. cit. p. 65)

15 "O processo deve se estruturar de maneira tecnicamente capaz de permitir a prestação das formas de tutela prometidas pelo direito material. De modo que entre as tutelas dos direitos e as técnicas processuais deve haver uma relação de adequação. No entanto, essa relação de adequação não pergunta mais sobre as formas de tutela, mas a respeito das técnicas processuais". (MARINONI, Luiz Guilherme. Tutela de urgência e tutela da evidência - soluções processuais diante do tempo da justiça. São Paulo: Editora Revista dos Tribunais, 2018, p. 28)

${ }^{16}$ MARINONI, 2018, op. cit. p. 29

${ }^{17}$ MARINONI, 2018, op. cit. p. 30
} 
cautelar antecedente, ou como incidente processual. E a tutela da evidência podendo ser efetivada sem o caráter de urgência, mas apenas com base na alta probabilidade do direito invocado.

\section{TUTELA DA EVIDÊNCIA}

Não há uma descrição normativa para a tutela da evidência, embora ela possa ser deduzida das hipóteses legais para a sua eventual concessão e do fato de que para tal não se exige a urgência características das demais formas de tutela provisória, como o perigo de dano ou risco ao resultado útil do processo, mas sim um juízo de probabilidade (que deve ser alta) sobre o direito para o qual a parte pleiteia a proteção estatal.

Ao definir a tutela da evidência, Eduardo Lamy, embora recorde que as hipóteses legais não se resumem àquelas do artigo 311 do CPC, deixa clara a sua vinculação à elevada probabilidade do direito, nos termos da lei. ${ }^{18}$

Algumas descrições doutrinárias caminham no sentido de afirmar o caráter de tutela antecipada da tutela da evidência, em certa medida, correspondente ao espaço ocupado pela possibilidade prevista no artigo 273 , inciso II e $\$ 6^{\circ}$ do CPC/1973, em parte repetido em parte nas hipóteses do artigo 311 do CPC/2015 ${ }^{19}$.

Parte da doutrina destaca na tutela da evidência, a ideia de defesa infundada, ou de sua fragilidade, de tal modo que o exercício do direito de defesa represente um abuso que possa ser considerado como um ganho indevido de tempo no processo por parte do réu ${ }^{20}$.

\footnotetext{
18 “A tutela da evidência é o tipo de tutela provisória que satisfaz os efeitos da tutela jurisdicional sem que haja perigo de dano, mas apenas altíssima probabilidade de acolhimento do direito, assim prevista em lei. Não se funda na urgência do caso, e sim na evidência do sistema jurídico”. (LAMY, 2018, op. cit. p. 19)

${ }^{19}$ Para Leonardo Greco: "Assim, pode definir-se a tutela da evidência, como a tutela antecipada que acolhe no todo ou em parte o pedido principal do autor para tutelar provisoriamente, independentemente da urgência, provável direito cuja existência se apresente prima facie indiscutível, nos casos previstos no artigo 311 do Código de 2014/2015”. (GRECO, Leonardo. A tutela da urgência e a tutela da evidência no Código de Processo Civil 2014/2015. Revista Eletrônica de Direito Processual, Ano 8, volume XIV, junho/dezembro, 2014, Rio de Janeiro.)

${ }^{20}$ Essa é a visão esboçada por Luiz Guilherme Marinoni, que assim descreve a tutela da evidência: “O Código de 2015, na linha do artigo 273, II, do Código de 1973, instituiu uma técnica processual destinada a viabilizar a tutela do direito do autor quando os fatos constitutivos do direito são incontroversos ou evidentes e a defesa é infundada, e, portanto, quando o exercício da defesa pode ser visto como um abuso. Bem vistas as coisas, tal técnica de tutela jurisdicional destina-se a viabilizar a distribuição do ônus do tempo do processo". (MARINONI, Luiz Guilherme. Tutela de urgência e tutela da evidência - soluções processuais diante do tempo da justiça. São Paulo: Editora Revista dos Tribunais, 2018, p. 31)
} 
É certo que, ao deslocar o perigo de dano e o risco ao resultado útil do processo, ou seja, retirando o aspecto de urgência e de cautelaridade/liminaridade ${ }^{21}{ }^{22}$ da tutela admitida no artigo 311, o fundamento primordial deste dispositivo passou a repousar sobre a concepção de direito evidente.

\subsection{Direito evidente}

Em que sentido um direito poderia ser considerado evidente?

A disposição legal do artigo 311 reúne, sob suas hipóteses, dois vetores essenciais para a consideração de um direito como evidenciado ao juízo. Um destes vetores diz respeito à atuação do autor da ação e à sua obrigação (processual) de demonstrar seu direito material. O outro vetor diz respeito à atuação do réu e sua obrigação de se manifestar sobre o que the é demandado de forma consistente e capaz de tornar controverso o direito material sobre o qual se estabeleceu o conflito; um direito é evidenciado de pronto quando é demonstrado desde logo. ${ }^{23}$

Esta definição é importante. E indica, ao que parece, aquele que representa o vetor principal para a caracterização do direito evidente, qual seja, o direito considerado como tendo alto grau de probabilidade. Ou seja, embora o grau de probabilidade possa ser amparado ou apoiado na atuação (evasiva ou abusiva) do réu, não é da atuação do réu - e esta é uma afirmação que sabemos pode ser polêmica - que se extrairá a evidência do direito, mas sim da atuação do autor da ação, que, para a reivindicação da tutela provisória, precisa fazer a demonstração do direito pleiteado como evidente.

\footnotetext{
${ }^{21}$ Embora o parágrafo único do artigo 311 admita o deferimento de liminar inaudita altera parte, parte da doutrina tem se inclinado por considerar tal parágrafo único como inconstitucional. É o caso de Luiz Guilherme Marinoni. (Cf. MARINONI, Luiz Guilherme. Tutela de urgência e tutela da evidência - soluções processuais diante do tempo da justiça. São Paulo: Editora Revista dos Tribunais, 2018). Eduardo Lamy por sua vez, sustenta que: "Ao contrário do que dispõe o $\S$ único do art. 311, ao permitir a análise da tutela evidente inaudita altera parte, a complexidade dos próprios incisos II e III do dispositivo já indica o acerto no respeito ao contraditório para o melhor enquadramento do precedente e o amadurecimento das alegações de fato inerentes ao contrato de depósito. Não faz sentido concluir-se pela evidência sem respeitar o contraditório, portanto". (LAMY, Eduardo. Tutela provisória. São Paulo: Atlas, 2018)

${ }^{22}$ A constitucionalidade do parágrafo único do artigo 311 foi questionada na ADI 5492, ajuizada pelo governador do estado do Rio de Janeiro, e que tem como relator o ministro Dias Toffoli; ainda sem decisão.

23 "Um direito é evidenciado de pronto quando é demonstrado desde logo. Para a tutela da evidência, contudo, são necessárias a evidência do direito do autor e a fragilidade da defesa do réu, não bastando apenas a caracterização da primeira". (MARINONI, 2018, op. cit., p. 282).
} 
Procurando estabelecer uma noção de direito evidente Luiz Fux ${ }^{24}$ chegou a comparálo com o direito líquido e certo do mandado de segurança. ${ }^{25}{ }^{26}$

Tal noção, ainda que pretérita ao Código de Processo Civil de 2015, coloca ênfase sobre o aspecto central da prova, ou seja, do direito evidente como direito decorrente de prova sobre fatos ${ }^{27}$.

Pode-se recorrer a uma análise gramatical dos termos para uma melhor elucidação do ponto. O Dicionário Unesp do Português Contemporâneo descreve evidente como: (1) perceptível; visível; (2) óbvio; indiscutível; (3) comprovado; incontestável. E evidência como: (1) característica do que é evidente ou incontestável; indício; indicação; prova. (...)

Nesse sentido, o evidente deve ser tomado como aquilo devidamente demonstrado. O óbvio, o indiscutível, o incontestável, só o são, num cenário de contraditório, diante de uma demonstração. Veja-se que três das quatro hipóteses do artigo 311 exigem prova documental do direito. A única que não o faz é exatamente a do inciso I, o que torna tal hipótese, ao menos aparentemente, mais problemática, e por isso mesmo o objeto do presente artigo. Como adiante se verá, a consideração primordial, é que, ainda que não mencione a questão da prova, a hipótese do inciso I do artigo 311 também está a exigir direito evidente, e portanto, direito a ser demonstrado, se não integralmente, com grau de probabilidade elevada.

Não é demais recordar também que, a despeito da origem latina da palavra evidência, a palavra ing lesa de núcleo gráfico comum, evidence, é traduzida como prova. Entre nós,

\footnotetext{
${ }^{24}$ FUX, Luiz. A tutela dos direitos evidentes. Jurisprudência do Superior Tribunal de Justiça, Brasília, ano 2, número 16, p. 23-43, abril de 2000.

25 "O problema se põe no plano fático, sobre ser evidente ou não o direito demonstrado ao juízo para viabilizar a tutela sumária não cautelar, de satisfatividade plena e por vezes irreversível. Os fatos, como sabido, são levados ao juízo através das provas, razão pela qual, quando se aduz a direito evidente, diz-se direito evidenciado ao juízo através das provas. Essa característica tem natureza mista material e processual. Sob o ângulo civil, o direito evidente é aquele que se projeta no âmbito do sujeito de direito que postula. Sob o prisma processual, é evidente o direito cuja prova dos fatos sobre os quais incide revela-os incontestáveis ou ao menos impassíveis de contestação séria". (FUX, 2000, op. cit., p. 29)

${ }^{26}$ Para a comparação do direito evidente ao "direito líquido e certo" do mandado de segurança, conferir a seguinte passagem: "A expressão vincula-se àquelas pretensões deduzidas em juízo nas quais o direito da parte revela-se evidente, tal como o direito líquido e certo que autoriza a concessão do mandamus ou o direito documentado do exeqüente". (FUX, 2000, op. cit., p. 23/24)

${ }^{27}$ Sobre a questão da prova e suportes fáticos, diz Jordi Ferrer Beltran: Não é necessário elaborar uma argumentação detalhada para mostrar que aquilo que deve ser provado em juízo depende dos suportes fáticos aos quais as normas atribuem consequências jurídicas. Dessa forma, no processo dever-se-á provar a proposição que afirma a ocorrência do fato para fins de aplicação da consequência jurídica prevista pelo direito". (BELTRÁN, Jordi Ferrer. Prova e verdade no direito. São Paulo: Editora Revista dos Tribunais, 2017, op. cit. p. 52).
} 
como visto, a palavra evidência também tem o significado de algo cuja existência tem alta probabilidade, e também o significado de indício e sinal. De tal maneira que não seria coincidência o fato de três das quatro hipóteses do art. 311 exigirem prova documental. ${ }^{28}$

Ora, o elemento central do direito evidente é, portanto, a prova. Mesmo se consideradas hipóteses fora daquelas do artigo 311, como é o caso da previsão dos artigos 700 e 701 do CPC acerca da monitória, permanece decisivo considerar o direito evidente como direito evidenciado, ou seja, direito suportado sobre elementos probatórios que, se não lhe dão a certeza decisiva para o julgamento definitivo, ao menos demonstram a elevada plausibilidade.

Esta questão parece elementar, dada a base normativa do artigo 311, em seus incisos II, III e IV, bem como no caso dos artigos 700 e 701. Seria menos elementar ou dispensável nos casos do inciso I do artigo 311 ?

\subsection{Hipóteses do artigo 311 do CPC}

Para os propósitos do presente artigo a ordem de apresentação dos incisos será invertida, de modo a discorrer sobre os incisos II, III e IV e só ao final sobre a hipótese do inciso I.

2.2.1. Alegações de fato provadas documentalmente e tese firmada em julgamentos repetitivos ou súmula vinculante

A hipótese legal de tutela da evidência sob tal fundamento implica a combinação de alegações jurídicas e de fato. Em que ambas precisam ser demonstradas. As alegações de fato pela exigência de prova documental. As bases jurídicas pela demonstração de sua existência e, fundamentalmente, de sua adequação ao caso em julgamento ${ }^{29}$.

É relevante que se considere que será necessário, para a decisão, atenção para o artigo $489, \S 1^{\circ}$, IV do CPC, de sorte que não basta a invocação do precedente ou súmula, mas a

\footnotetext{
${ }^{28}$ YARSHELL, Flávio Luiz; e ABDO, Helena. As questões não tão evidentes sobre a tutela da evidência, in: Tutela Provisória. Coord. Cássio Scarpinella Bueno et. al. São Paulo: Saraiva, 2016.

${ }^{29}$ De acordo como Eduardo Lamy: Deve-se lembrar, entretanto, que o que vincula o julgador é sempre a ratio decidendi dos julgados que geraram esses casos repetitivos, assim como a ratio decidendi dos julgados que geraram a adoção de súmulas vinculantes. (LAMY, 2018, op. cit., p. 19)
} 
demonstração de sua adequação ao caso em julgamento, cabendo ao magistrado a indicação das semelhanças entre o caso concreto e os precedentes que fundamentam sua decisão. ${ }^{30}$

Assim, cabe ao autor fazer a prova dos fatos constitutivos de seu direito, e ao mesmo tempo sua subsunção ao entendimento da Suprema Corte, ao mesmo tempo que, seja necessário, ainda, o prosseguimento do feito para instrução e somente posterior julgamento definitivo. Neste particular, Marinoni sustenta que a razão de prosseguimento do feito está na necessidade de instrução dilatória, derivada de alegações de fato cujo ônus da prova é do réu $^{31}$, ao passo que EduardoLamy, considera que tal inciso só faz sentido caso se entenda que as alegações do autor, evidenciadas por documento, embora amparadas no entendimento de Corte Suprema, demandam instrução probatória. ${ }^{32}$

Tomamos como posição mais coerente o segundo argumento, dado que a evidenciação do direito para os fins próprios da concessão da tutela provisória, deve ser feita pelo autor. O próprio inciso II (e assim também o III), diferente dos incisos I e IV, não coloca a atuação do réu como algo que deva ser levado em conta para efeitos da tutela provisória. Mas aqui surge um aspecto que pode tornar pouco útil a previsão da tutela da evidência nos casos do inciso II: se o direito estiver demonstrado ao ponto de não restar dúvida ao juiz, melhor caminho seria o julgamento antecipado, e, neste caso, a tutela provisória da evidência, cuja pretensão seria a redução do tempo processual, resultaria no seu oposto. A temática será analisada no ponto seguinte do artigo.

Por fim, boa parte da doutrina tem se inclinado por entender que a exigência de precedentes em julgados de casos repetitivos e súmula vinculante seria apenas exemplificativa, e que as possibilidades seriam mais abrangentes, integrando outros precedentes previstos no artigo 927, do $\mathrm{CPC}^{33}$.

\subsubsection{Pedido reipersecutório fundado em prova documental do contrato de depósito}

\footnotetext{
${ }^{30}$ SCHEIDT, Emiliane. A tutela de evidência no novo Código de Processo Civil. REVISTA DA ESMESC, v.23, n.29, p. 183-206, Florianópolis, 2016.

${ }^{31}$ MARINONI, 2018, op. cit., p. 335

${ }^{32}$ LAMY, 2018, op. cit., p. 19

${ }^{33}$ YARSHELL e ABDO,2016, op. cit., p. 460 ; LAMY 2018, op. cit., p. 21; MARINONI, 2018, op. cit., p. 336
} 
Trata-se de situação especial, voltada a princípio apenas para os contratos de depósito e à busca de devolução da coisa dada em depósito. O CPC/1973 previa ação própria para situações em que o direito fosse o de restituição da coisa depositada.

Eduardo Lamy, recorda que o CPC de 2015 extinguiu, assim, substituindo-a pela possibilidade de tutela provisória pela evidência, identificada no inciso III do art. 311. No artigo 902 do CPC/1973 o réu era citado para em 05 (cinco) dias entregar a coisa, ou contestar a ação. Mas por disposição do artigo 903, caso o réu contestasse a ação, esta seguiria o rito ordinário.

A hipótese do inciso III também exige a prova documental, e a princípio não está fundada em atuação do réu, mas tão somente na capacidade do autor de demonstrar a evidência de seu direito, através de prova documental. Marinoni considera que a "prova documental do contrato de depósito" é insuficiente. ${ }^{34}$

Tal inciso, assim, como o inciso anterior (II) carrega, talvez, uma razoável incongruência nos propósitos da técnica da evidência. De um lado porque para terem algum sentido, sobretudo para os que associam evidência e tempo do processo, as hipóteses fariam sentido se possível a concessão de liminar, o que é visto como inconstitucional por parte da doutrina, como já mencionado ${ }^{35}$. Por outro lado, se o direito estiver cabalmente demonstrado, faria muito mais sentido o julgamento antecipado da lide e não a tutela da evidência. Essas incongruências poderão, como o tempo, tornar inócua, ou pouco utilizável, a previsão legal.

2.2.3. Petição inicial instruída com prova documental suficiente dos fatos constitutivos a que o réu não oponha prova capaz de gerar dúvida razoável

Nesta hipótese há uma combinação de prova documental, com uma atuação do réu que, em sua contestação, não suscite dúvida capaz de colocar em questão os fatos constitutivos do direito do autor, ainda que através de defesa indireta.

\footnotetext{
34 “ (.... é indispensável a prova do contrato e da mora na entrega da coisa. É simples: só há evidência, capaz de justificar a distribuição do ônus do tempo do processo mediante a imediata outorga da tutela do direito, quando os fatos constitutivos não estão na dependência de demonstração". (MARINONI, op. cit., p. 336)

${ }^{35}$ Em sentido diverso, considerando que: "a hipótese prevista no inciso II do art. 311 do CPC 2015 só tem sentido se combinada com a previsão do parágrafo único daquele dispositivo, ou seja, se for proferida em caráter liminar. (YARSHELL e ABDO, 2016, op. cit., p. 461).
} 
Portanto, exige-se do autor o aporte de prova documental suficiente para comprovar os fatos que alega (fatos constitutivos do seu direito), e de outra parte que o que réu se abstenha de apresentar qualquer prova capaz de gerar dúvida razoável sobre o alegado pelo autor. ${ }^{36}$

Remanesce alguma dúvida acerca do direito do autor, mas é o comportamento do demandado ao contestar, e não opor provas capazes de gerar dúvida, que atesta a evidência. ${ }^{37}$

Veja-se que, correta a afirmação de que o comportamento do réu atesta a evidência. Isto porque a simples inação do réu não teria qualquer utilidade ou sentido, se não houvesse prova documental dos fatos constitutivos por parte do autor.

É tido como a hipótese que melhor se aproxima do modelo teórico pensado para a tutela da evidência.

\subsubsection{Abuso do direito de defesa ou manifesto propósito protelatório}

Para Marinoni ${ }^{38}$, estar-se-ia, no caso do inciso I do artigo 311, diante de "cláusula geral", base da tutela da evidência. O abuso do direito de defesa e a atuação protelatória do réu seria exatamente o que a legislação estaria tentando coibir ao firmar uma autorização ao juiz para decidir o feito, de forma não definitiva, mas já com a possibilidade de alteração fática no plano do direito material, através da tutela provisória.

Tal cláusula geral serviria como fundamento principal da ideia de inversão ou distribuição do tempo processual, dado que a continuidade do processo, diante de uma atuação abusiva ou protelatória do réu, se faria a seu ônus, dado que contra ele poderia recair uma decisão já com força executiva quanto ao direito sobre o qual pende a controvérsia.

Inobstante essas considerações, é preciso considerar que, embora uma atuação abusiva ou protelatória possa representar indício quanto à razão das alegações do autor, é necessário que tal atuação se dê contra direito demonstrado com alto grau de probabilidade. Ou seja, não basta alegar um direito evidente, é preciso demonstrá-lo como evidente. É necessário que ele se torne evidente para o juiz através da prova trazida ao processo.

\footnotetext{
${ }^{36}$ SCHEIDET, 2016, op. cit., p. 189

${ }^{37}$ LAMY, 2018, op. cit., p. 22.

${ }^{38}$ MARINONI, Luiz Guilherme. Tutela de urgência e tutela da evidência - soluções processuais diante do tempo da justiça. São Paulo: Editora Revista dos Tribunais, 2018.
} 
Com isso se poderia dizer que a verdadeira cláusula geral da tutela da evidência é a existência de um direito evidente, sem o que não há como deferir o pedido de tutela provisória.

\subsection{Tutela da evidência e julgamento antecipado}

Questão de relevância para a análise da tutela da evidência, e que comparece ao debate doutrinário é a distinção entre esta técnica da tutela provisória, baseada em cognição sumária, e a possiblidade de julgamento antecipado da lide, prevista nos artigos 355 e 356 do CPC, baseada e cognição exauriente.

Costa e Oliveira ${ }^{39}$, procurando estabelecer um quadro comparativo, partem da definição de tutela da evidência como sendo aquela concedida com base em direito líquido e certo, em que o julgamento antecipado decorreria do cumprimento de princípios constitucionais. $^{40}$

Ora, veja-se que a distinção que se estabelece entre tutela da evidência e julgamento antecipado do processo está fundamentada especialmente na técnica de cognição utilizada em cada caso. Enquanto num se estaria diante de uma cognição sumária, e, portanto, impedida de dar ao feito uma solução definitiva ao conflito processual, mas permitindo-lhe a execução do direito tido por evidente (tutela da evidência), no outro, se estaria diante de cognição definitiva, capaz de dar solução definitiva ao conflito de direito material.

De comum entre ambos os casos a possibilidade de execução do direito material, ou seja, a possibilidade de efetivação do direito imediatamente.

\footnotetext{
39. COSTA, Marina Chaves Fernandes; OLIVEIRA, Frank Augusto de. É possível estabelecer critérios que diferenciem a tutela de evidência prevista no artigo 311, II do NCPC, do julgamento parcial do mérito previsto no art. 356, II, c/c 355, I, NCPC? In: Processo, jurisdição e efetividade da justiça III [Recurso eletrônico online] organização $\quad$ CONPEDI. Disponível em https://www.conpedi.org.br/publicacoes/roj0xn13/1743z27d/Y30muA3xAh3CQbN6.pdf (acessado em 11 de novembro de 2018)

40 "Portanto, conclui-se que a tutela de evidência é aquela concedida com base no direito líquido e certo, dispensado o perigo da demora, àquela parte que possui maior probabilidade de obter sucesso no provimento definitivo, fundamentada na garantia à duração razoável do processo (art. $5^{\circ}$, LXXVIII, CF) objetivando reverter o ônus da demora processual. (...) Com receio de se ressaltar o óbvio, o julgamento antecipado é fundado em cognição exauriente, pois como exposto, não se pula a fase probatória, apenas percebe-se que, a par desta, a cognição já se exauriu, possuindo a mesma validade e legalidade que um julgamento que percorreu todas as fases do procedimento. $\mathrm{O}$ julgamento antecipado é uma técnica que atende às garantias do devido processo legal, contraditório e ampla defesa, art. $5^{\circ}$, LIV, LV, CF, também, àquela que garante a celeridade processual, evitando dilações desnecessárias, art. $5^{\circ}$, LXXVIII, CF”. (COSTA e OLIVEIRA, op. cit., p. 228 e 235)
} 
A proximidade entre as duas hipóteses provoca algumas reflexões controvertidas acerca da aplicação da tutela da evidência, sobretudo a partir da reflexão de que o tempo seria um elemento de fundamento da tutela provisória baseada na evidência, ainda mais se considerado que a tutela da evidência teria, para sua concessão, critérios mais rígidos do que o julgamento antecipado. ${ }^{41}$

Tal questão é levantada em função da previsão do inciso II do artigo 311 do CPC (alegações de fato comprovadas documentalmente e houver tese firmada em recursos repetitivos ou súmula vinculante $)^{42}$. Mas não há nada que objete considerar que seja possível adotar a mesma visão em relação as hipóteses dos incisos III e IV, também a exigir prova documental do direito.

Observando pela ótica da decisão do juiz, havendo prova documental consistente, e, a partir da contestação do réu o julgador considerar que não há mais prova a produzir, poderá julgar o mérito, realizando a tutela jurisdicional na forma definitiva (artigo 355, I do CPC); e bem assim quando considerar que um ou mais pedidos mostrarem-se incontroversos ou estiverem em condições de imediato julgamento.

Efetivamente, ao que parece, o espaço para a tutela da evidência ficou confinado entre, de um lado, a tutela provisória da urgência, diante da demonstração de perigo de dano o risco ao resultado do processo, e de outro, pela possibilidade de julgamento antecipado do mérito, de todo o direito material controvertido, ou de um ou alguns dos pedidos.

Pela ótica da distribuição do tempo do processo, com a qual pretendemos dialogar adiante, a tutela da evidência, poderia se tornar, em muitos casos, um caminho mais longo e demorado e não necessariamente um caminho mais curto e célere a efetivação do direito material ${ }^{43}$.

\footnotetext{
41 "A priori, parece estranho que uma decisão capaz de se tornar imutável necessite de menos requisitos do que aquela provisória. Se é possível conseguir um julgamento do mérito definitivo, por que haveria a necessidade de se fazer um pedido de tutela provisória de evidência que possui requisitos mais rígidos?" (COSTA e OLIVEIRA, op. cit., p. 238)

${ }^{42}$ Eduardo Lamy sustenta o mesmo ao afirmar: "O inciso só faz sentido caso se entenda que as alegações do autor, evidenciadas por documento, embora amparadas em entendimento de Corte Suprema, demandam instrução probatória. Caso contrário, haveria julgamento antecipado do mérito". (LAMY, 2018, op. cit., p. 19). ${ }^{43}$ COSTA e OLIVEIRA, no artigo antes mencionado, trazem uma outra questão, o risco de baixa utilização da técnica em relação à tutela de urgência: "A tutela de evidência, se comparada com a tutela de urgência, ainda é pouco utilizada na praxe forense. Comparativamente, ao se buscar 'tutela de evidência' na jurisprudência do Superior Tribunal de Justiça, encontram-se, apenas, 27 acórdãos, ao tempo que na busca pela expressão 'tutela de urgência', obtém-se 319 resultados". (COSTA e OLIVEIRA, op. cit., p. 228).
} 
Ademais, o tempo do processo enseja discussões mais complexas na sua relação com o uso de técnicas processuais com vistas à tutela jurisdicional. É o que analisaremos a seguir.

\section{DIREITO EVIDENTE E DISTRIBUIÇÃO DO TEMPO DO PROCESSO}

A presente abordagem tomou como um ponto problemático na discussão sobre a tutela da evidência a seguinte questão: Dado que a concessão da tutela provisória baseada em evidência, prevista no artigo 311, I do CPC demanda a comprovação de um "direito evidente", é possível situar o tempo do processo, e sua distribuição, como um fundamento (implícito) da tutela da evidência e sua concessão?

Dizer implícito aqui corresponde a considerar que, de regra, o único momento em que o tempo do processo está considerado como elemento do deferimento da tutela provisória é aquele previsto no inciso I do artigo 311, dado que nos demais a evidência tem como fundamento nuclear a presença de um direito evidente amparado em prova documental.

Duas questões-problema poderiam ser articuladas a partir daí: (1) se o disposto no inciso I, assumido como "cláusula geral" da tutela da evidência, inverteria a lógica interna do direito evidente, ou seja, deslocaria a demonstração da evidência da atuação comprobatória do autor, para o comportamento abusivo e protelatório do réu; (2) se o tempo do processo, de um modo geral serviria como fundamento para a concessão da tutela da evidência.

\subsection{O tempo como fundamento das regras processuais recentes}

Tomada como uma espécie de lugar comum"no discurso de crítica ao funcionamento e às estruturas do Poder Judiciário, a afirmação sobre a demora no julgamento, ou a "morosidade judicial" como se tornou conhecida, alcançou seu ápice na Reforma do Judiciário aprovada pela Emenda Constitucional 45/2004.

Por aquela reforma, o direito à razoável duração do processo alcançou o status de direito fundamental, integrando o artigo $5^{\circ}$. da Constituição Federal (inciso LXXVIII). 
Revista Eletrônica de Direito Processual - REDP.

Rio de Janeiro. Ano 15. Volume 22. Número 3. Setembro a Dezembro de 2021

Periódico Quadrimestral da Pós-Graduação Stricto Sensu em Direito Processual da UERJ

Patrono: José Carlos Barbosa Moreira (in mem.). ISSN 1982-7636. pp. 1125-1148

www.redp.uerj.br

As conclusões aparentemente irrecusáveis ${ }^{44}$ sobre a necessidade de se tomar medidas para a aceleração da tomada de decisões pelo Judiciário influenciaram de modo bastante decisivo a construção das novas normas processuais no Código de Processo Civil de 2015.

Ao discorrer sobre os motivos da reforma processual e os trabalhos da comissão de juristas encarregada de elaboração do Anteprojeto do Novo Código de Processo Civil, o ministro Luiz Fux apontou para o ataque à morosidade como fundamento da proposta. ${ }^{45} 46$

E na sequência do argumento, em relação especificamente à tutela da evidência, reitera Fux a perspectiva traçada. ${ }^{47}$

Como se vê, a questão do tempo processual, ou "tempo da justiça" (como descreve Luiz Guilherme Marinoni), aparece como um fundamento para a reforma processual de 2014/2015, bem assim como para o instituto específico da tutela da evidência.

\footnotetext{
${ }^{44}$ Para uma perspectiva crítica da questão conferir o que escrevi em trabalho anterior, especialmente a passagem a seguir: "Demora e excesso de litígios comporiam então faces de uma mesma moeda. Mas não deixa de ser paradoxal esta conclusão, considerando que a reiterada demora nos julgamentos tenderia a surgir como um fator desestimulante da busca de solução de conflitos pela via judicial. O Judiciário é tido como lento, mas se recorre a ele mais do que antes. Este paradoxo pode levar à conclusão de que, embora a morosidade judicial tenha conquistado a quase unanimidade das opiniões, há interesses e visões bastante distintos e contraditórios entre os seus críticos, ao ponto de se poder previamente concluir também que demora e excesso não são necessariamente um problema para todos". (ROSALEN, Volnei. Tempo do processo - novo paradigma ou velho paradoxo. Revista do CEJ, Brasília, Ano XVIII, n. 64, p. 79-88, set./dez. 2014.p. 79). E a citação do ministro Nelson Jobim que tomei como referência para esta leitura: "Não se excluam todos aqueles que estão interessados na função, principalmente um interessado na demanda que terá que financiar a disputa entre a autonomia e a soberania do juiz de $1^{\circ}$. Grau em relação à matéria objeto do processo. [...] Apostar na apelação é uma decisão comercial pelo ganho de dinheiro. Alguém está interessado nisso, que é virtualmente "devedor", e, de outro lado, aquele que, em cima da demanda, reproduz-se socialmente". (JOBIM, Nelson. O poder judiciário no Brasil atual. Série Cadernos do CEJ. Caderno 12. Brasília: CEJ, 1997, p. 28)

45 "Deveras, apesar das reformas pontuais empreendidas desde a década de 1990, inclusive a que se efetivou após a Emenda Constitucional n ${ }^{\circ} 45$, denominada "reforma do Judiciário", e que se implementou mediante a edição de inúmeras leis processuais esparsas, o defeito contemporâneo do processo consistente na sua 'irrazoável duração' e que se manteve inalterado impunha um aprofundamento no estudo das causas da tão decantada 'morosidade da justiça"'. (FUX, Luiz. O novo processo civil. Rev. TST, Brasília, vol. 80, no 4, out/dez 2014, p. 265)

${ }^{46}$ Do mesmo texto: "A ideia de que 37 (trinta e sete) anos depois do Código de 1973 impunha-se elaborar um novo ordenamento, atento aos novos reclamos eclipsados na cláusula constitucional da "duração razoável dos processos", a Comissão, à luz desse ideário maior, entendeu erigir nóveis institutos e abolir outros que se revelaram ineficientes ao longo do tempo, com o escopo final de atingir a meta daquilo que a genialidade do processualista denominou de uma árdua tarefa para os juízes: 'Fazer bem e depressa'”. (FUX, 2014, op. cit., p. 266). O artigo enumera outros exemplos como fundamento: o Projeto de Florença, de Mauro Capeletti e Bryan Garth; conclusões da XXII Jornadas Panamericanas de Direito Processual; Jornadas Íbero-Americadas de Direito Processual de 2006; e palavras do jurista Eduardo Couture, como argumentos na mesma direção.

47 “A novidade também se operou quanto aos direitos líquidos e certos de uma parte em face da outra. Entendeu a Comissão que, nessas hipóteses em que uma parte ostenta direito evidente, não se revelaria justo, ao ângulo do princípio da isonomia, postergara a satisfação daquele que se apresenta no processo com melhor direito, calcado em prova inequívoca, favorecendo a parte que, ao menos prima facie, não tem razão". (FUX, 2014, op. cit., p. 283)
} 


\subsection{0 tempo como fundamento da tutela da evidência: demora processual não evidencia $^{48}$ direito}

Ao permitir ao juiz uma decisão em qualquer momento do processo que dá à parte a satisfação (execução) do direito material pleiteado o artigo 311 do CPC efetivamente pode ser compreendido como técnica de encurtamento do tempo do processo.

Do ponto de vista da efetivação do direito material é possível considerar que a adoção de técnicas processuais e procedimentos adequados devem ensejar o encontro do direito processual com o direito material e sobretudo do direito processual com os direitos fundamentais $^{49}$.

E é possível também considerar as técnicas processuais como um modo de relacionar a efetivação do direito material ao tempo processual ${ }^{50}$.

Sobre a relevância do tempo processual como fundamento das técnicas tutelares voltadas aos direitos evidentes, afirma Fux ${ }^{51}$ que o tempo é fator de denegação de justiça.

No mesmo sentido, Luiz Guilherme Marinoni, propõe que a técnica da tutela da evidência tem como sentido a inversão do ônus do tempo do processo, baseada na

\footnotetext{
${ }^{48}$ Embora possa parecer óbvio, aqui "evidencia" é verbo, com sílaba tônica em "cia".

${ }^{49}$ Essa é a meu sentir, a visão de Eduardo Lamy, conforme se depreende da seguinte passagem: "Trata-se de uma forma de pensar o direito processual como instrumento para a efetivação do direito material, passando pela reconceituação de vários dos institutos essenciais do processo, o que justificaria, até mesmo, definirem-se as bases para uma nova teoria geral da disciplina: uma teoria que não esteja fundada apenas nos institutos da relação jurídica processual, da ação, da jurisdição e da defesa, mas também, e principalmente, nos direitos fundamentais, reestruturando o processo a partir dos seus princípios constitucionais sem, contudo, deixar de reconhecer importância aos institutos". (LAMY, 2014, op. cit., p. 310)

${ }^{50}$ É o que propõe, a meu ver Luiz Guilherme Marinoni, como se vê nesta passagem: "Para que se possa compreender a relação entre a cognição parcial e a ideologia dos procedimentos, cabe observar que o procedimento de cognição parcial privilegia os valores certeza e celeridade, ao permitir o surgimento de uma sentença com força de coisa julgada material em um tempo inferior àquele necessário ao exame de toda extensão da situação litigiosa, mas deixa de lado o valor “justiça material"”. (MARINONI, 2018, op. cit., p. 30) 51 "O tempo é fator de denegação de justiça e sob essa ótica deve ser a exegese acerca dos poderes e deveres do juiz quanto à rápida solução dos litígios e quanto ao acesso à justiça na sua acepção de efetividade e de cumprimento do devido processo legal". (FUX, 2000, op. cit., p. 16)
} 
inconsistência dos elementos apresentados pela defesa, portanto visto o tempo do processo como um ônus. ${ }^{52}{ }^{53}$

Flávio Yarshell e Helena Abdo seguem em sentido semelhante a ideia de que a tutela da evidência estaria dirigida a neutralizar o risco de danos decorrentes da demora processual. $^{54}$

Como ser vê, o tempo de duração do processo (ou simplesmente "tempo do processo") aparece como um fundamento relevante para a prestação de toda a tutela jurisdicional e no particular em relação à tutela da evidência.

Mas poder-se-ia considerar o tempo do processo ("tempo da justiça" no dizer de Marinoni) como finalidade, ou fim em si do processo? Parece que não. Tanto no processo, visto como descrição genérica de meio para a solução do direito controvertido, como no processo visto pela ótica da técnica processual voltada à efetivação do direito material, o tempo, ou melhor dizendo, o encurtamento do tempo pode ser visto como uma consequência, mas não como uma finalidade.

Se é possível argumentar que o um menor tempo seja uma medida de efetividade da prestação jurisdicional, é possível também, em contrapartida, poder-se-ia alegar que em determinadas situações um maior tempo do processo também teria como pressuposto uma maior efetividade da tutela jurisdicional.

Assim, embora o tempo processual possa ser tomado como referência para as reformas processuais e até mesmo como medida da efetividade da tutela jurisdicional, não se pode dizer que essa seja a finalidade precípua da tutela da evidência. Ou mesmo (e aqui divergimos em relação à visão de Marinoni) considerar que a tutela da evidência, como

\footnotetext{
52 "A tutela da evidência, assim, permite a distribuição do ônus do tempo do processo de acordo com a evidência do direito do autor e com a fragilidade de defesa do réu, afastando-se da tutela antecipada baseada em perigo de dano em razão do seu diferente fundamento e diversa finalidade. Enquanto a tutela antecipada propriamente dita tem como fundamento a urgência e como objetivo a imediata tutela do direito para evitar dano, a tutela da evidência tem como fundamento a evidência do direito e a inconsistência da defesa e como fim a inversão do ônus do tempo do processo". (MARINONI, 2018, op. cit., p. 44).

53 "Note-se que esta espécie de técnica de tutela dos direitos é o resultado da admissão de que: i) o tempo do processo não pode ser jogado nas costas do autor, como se fosse o culpado pela demora inerente à investigação dos fatos; ii) portanto, o tempo do processo deve ser visto como um ônus; iii) o tempo deve ser distribuído entre os litigantes em nome da necessidade de o processo trata-los de forma isonômica". (MARINONI, 2018, op. cit., p. 277)

54 " A utilidade da tutela da evidência não estaria, pois, dirigida a neutralizar um perigo de dano irreparável ou de difícil reparação (periculum in mora), mas sim a neutralizar aquele dano decorrente da normal e inevitável demora do processo, o chamado dano marginal". (YARSHEL; ABDO, op. cit., p. 456)
} 
técnica, impõe uma redistribuição do ônus do tempo do processo. Ora, se o autor não evidencia (aqui semântica e gramaticalmente como conjugação do verbo evidenciar, e tendo, portanto, como sílaba tônica o cia) o seu direito, não é possível tomar a atuação do réu ou mesmo a demora do processo como demonstração dessa evidência.

Dito de forma direta: a demora não evidencia direito. Ou, o tempo não é evidência.

Isto porque o direito fundamental à razoável duração do processo é um direito de todas as partes. Significa aqui dizer que, embora alguns considerem que o núcleo de tal direito fundamental é a aceleração do julgamento dos processos, a existência de conflito quanto ao direito e, portanto, de contraditório, impõe que se considere que a razoável duração do processo é direito de ambas as partes. Isso significa que razoável duração do processo não é necessariamente processo com tempo mais curto, mas sim com o tempo necessário à resolução do conflito material. Isso pode significar mais tempo, e não menos tempo.

Pode-se tomar o problema pela ótica da prova, ou seja, da distribuição do tempo necessário à produção da prova, como aventado por Marinoni. ${ }^{55}$

Mas posta a questão desta forma, o processo, ao diferente da pretensão afirmada, torna-se quase um fim em si mesmo, distanciando-se e não aproximando-se do seu propósito de corresponder, ao máximo, ao direito material discutido e sobre o qual se estabeleceu o conflito.

Em síntese como se tem afirmado, "um direito é evidenciado de pronto quando é demonstrado desde logo" ${ }^{, 56}$. Ou ainda, daquelas pretensões nas quais o direito da parte revela-se evidente, tal como o direito líquido e certo.

É a esse fundamento que se prende a tutela da evidência, qual seja, a capacidade da parte de demonstrar a presença do direito material para o qual pleiteia a tutela.

Ainda que se possa alegar a "cláusula geral" do abuso de defesa e atuação protelatória do réu, ali também, o direito do autor demanda, ainda assim, evidências que permitam formar uma convicção de probabilidade de direito para a decisão. Ou seja, o direito não é evidente aos olhos do autor, mas evidentes aos olhos do juiz.

\footnotetext{
${ }^{55}$ Porém, aqui não importa saber quem deve provar ou quando o ônus da prova deve ser invertido, mas quem deve suportar o tempo necessário à produção da prova. Se o ônus da prova dos fatos litigiosos deve ser repartido entre o autor e o réu na medida do que estes alegam, cabe indagar se o tempo para a produção da prova também não deve ser repartido de acordo com a mesma regra. (MARINONI, 2018, op. cit., p. 284)

${ }^{56}$ MARINONI, 2018, op. cit., p. 282
} 
E para que fique claro que a intenção do presente artigo não é produzir uma justificativa da demora processual decorrente da atuação dos membros do Judiciário, é preciso afirmar que: colocar o tempo na base da tutela da evidência desloca a questão central, qual seja, da evidência do direito, e mais, coloca uma premissa equivocada ao trabalho do juiz (e de todo o Judiciário). Julgar em velocidade compatível é uma obrigação (do juiz e de todo o Judiciário) de natureza administrativa, decorrente da posição dos agentes públicos na prestação de um serviço (a jurisdição) que é público, portanto obrigações para com a sociedade que remunera esses agentes para tal ${ }^{57}$, e não uma questão de escolha desta ou daquela técnica de tutela.

\section{CONSIDERAÇÕES FINAIS}

Como visto, a tutela provisória baseada na evidência constituiu uma importante novidade, que, embora já presente no CPC 1973 (art. 273, II e $\S 6^{\circ}$.), foi adotada de forma delimitada no CPC 2015.

É possível afirmar com segurança que, dado o histórico antecedente à reforma processual e os fundamentos apresentados pela Comissão de Juristas encarregada pelo anteprojeto, que as alterações das normas processuais tiveram como um dos seus aspectos motivadores a necessidade de vencer problemas de demora no julgamento que decorriam de normas processuais.

Embora a aceleração do processo seja uma das pretensões da reforma, e possa ser considerada uma consequência da adoção de técnicas processuais fundadas na tutela provisória, não se trata de um fim ou finalidade dos procedimentos adotados, no caso da tutela da evidência.

A tutela da evidência baseia-se na demonstração do direito evidente do autor a partir da exigência de demonstração documental quanto ao direito material sobre o qual recai o conflito. Baseia-se também na incapacidade do réu de, em sua defesa, fundar dúvida razoável em face das provas apresentadas pelo autor.

\footnotetext{
${ }^{57}$ Para o cotejo de informações sobre excesso de demandas processuais que poderiam ser invocadas contra essa afirmação (e outras questões polêmicas sobre a atuação do Judiciário no Brasil) conferir: ROSALEN, Volnei. Judiciário e política - fatos e versões da crise do Judiciário do Brasil a partir de sua estrutura e dos litígios. Curitiba: Editora Juruá, 2018.
} 
A necessidade de um grau elevado de probabilidade do direito pleiteado, através de provas documentais, aproxima a tutela provisória da evidência da tutela definitiva obtida através de julgamento antecipado do mérito, o que pode tornar a tutela da evidência uma possibilidade pouco atraente em termos processuais, e até mesmo, do ponto de vista do tempo, mais demorada.

O julgamento breve dos processos, evitando o prolongamento desnecessário das lides, é obrigação administrativa e funcional. Ou seja, o tempo processual não corresponde à evidência do direito.

\section{REFERÊNCIAS}

BEDAQUE, José Roberto dos Santos. Tutela provisória: considerações gerais. In: CARMONA, Carlos Alberto et. al. O Novo Código de Processo Civil - questões controvertidas. São Paulo: Atlas, 2015.

BELTRÁN, Jordi Ferrer. Prova e verdade no direito. São Paulo: Editora Revista dos Tribunais, 2017.

BOBBIO, Norberto. O positivismo jurídico - lições de filosofia do direito. Tradução de Márcio Pugliesi, Edson Bini e Carlos E. Rodrigues. São Paulo: Editora Ícone, 1995.

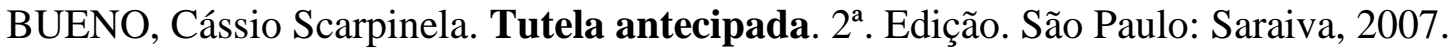

COSTA, Marina Chaves Fernandes; OLIVEIRA, Frank Augusto de. É possível estabelecer critérios que diferenciem a tutela de evidência prevista no artigo 311, II do NCPC, do julgamento parcial do mérito previsto no art. 356, II, c/c 355, I, NCPC?. In: Processo, jurisdição e efetividade da justiça III [Recurso eletrônico online] organização CONPEDI. Disponível em https://www.conpedi.org.br/publicacoes/roj0xn13/1743z27d/Y30muA3xAh3CQbN 6.pdf (acessado em 11 de novembro de 2018)

DICIONÁRIO UNESP DO PORTUGUÊS CONTEMPORÂNEO. Org. Francisco S. Borba. São Paulo: Unesp, 2004.

FUX, Luiz. A tutela dos direitos evidentes. Jurisprudência do Superior Tribunal de Justiça, Brasília, ano 2, número 16, p. 23-43, abril de 2000. . O novo processo civil. Rev. TST, Brasília, vol. 80, no 4, out/dez 2014. 
GRECO, Leonardo. A tutela da urgência e a tutela da evidência no Código de Processo Civil 2014/2015. Revista Eletrônica de Direito Processual, Ano 8, volume XIV, junho/dezembro, 2014, Rio de Janeiro.

JOBIM, Nelson. O poder judiciário no Brasil atual. Série Cadernos do CEJ. Caderno 12. Brasília: CEJ, 1997.

LAMY, Eduardo; RODRIGUES, Horácio Wanderlei. Teoria Geral do Processo. 4a . Edição. São Paulo: Atlas, 2016.

LAMY, Eduardo. Tutela provisória. São Paulo: Atlas, 2018. . Considerações sobre a influência dos valores e direitos fundamentais no âmbido da teoria processual. Sequiência (Florianópolis), n. 69, p. 301-326, dez. 2014

MARINONI, Luiz Guilherme. Tutela de urgência e tutela da evidência - soluções processuais diante do tempo da justiça. São Paulo: Editora Revista dos Tribunais, 2018.

ROSALEN, Volnei. Judiciário e política - fatos e versões da crise do Judiciário do Brasil a partir de sua estrutura e dos litígios. Curitiba: Editora Juruá, 2018.

. Tempo do processo - novo paradigma ou velho paradoxo. Revista do CEJ, Brasília, Ano XVIII, n. 64, p. 79-88, set./dez. 2014.

SCHEIDT, Emiliane. A tutela de evidência no novo Código de Processo Civil. REVISTA DA ESMESC, v.23, n.29, p. 183-206, Florianópolis, 2016.

VIGLIAR, José Marcelo Menezes. Tutela Jurisdicional coletiva. São Paulo: Atlas, 2013. YARSHELL, Flávio Luiz; e ABDO, Helena. As questões não tão evidentes sobre a tutela da evidência, in: Tutela Provisória. Coord. Cássio Scarpinella Bueno et. al. São Paulo: Saraiva, 2016. 